\title{
openheart Comparative effectiveness of ACE inhibitors and angiotensin receptor blockers in patients with prior myocardial infarction
}

- Additional material is published online only. To view please visit the journal online (http://dx.doi.org/10.1136/ openhrt-2019-001010).

To cite: Ko D, Azizi P, Koh M, et al. Comparative effectiveness of ACE inhibitors and angiotensin receptor blockers in patients with prior myocardial infarction. Open Heart 2019;6:e001010. doi:10.1136/ openhrt-2019-001010

Received 10 January 2019 Revised 8 March 2019 Accepted 1 April 2019

Check for updates

C Author(s) (or their employer(s)) 2019. Re-use permitted under CC BY-NC. No commercial re-use. See rights and permissions. Published by BMJ.

${ }^{1}$ Institute for Clinical Evaluative Sciences, Toronto, Ontario, Canada

2University of Toronto, Toronto, Ontatio, Canada

${ }^{3}$ Western University of Health Services, Pomona, California, USA

Correspondence to Dr Dennis Ko; dennis.ko@ices. on.ca

\section{ABSTRACT}

Objective Although ACE inhibitors (ACEls) and angiotensin receptor blockers (ARBs) are commonly prescribed for patients with coronary artery disease, whether these medications are similarly effective is still a subject of intense debate. Our objective was to compare the clinical effectiveness of ACEls and ARBs in patients with prior myocardial infarction (MI).

Methods All residents older than 65 years, alive on 1 April 2012, with a prior MI were included. Propensity weighting was used to balance potentially confounding baseline covariates between the treatment groups. The primary outcome was a composite of cardiovascular death, hospitalisation for $\mathrm{Ml}$ or unstable angina at 3 years. Results Our cohort included 59353 patients with Ml; their mean age was 77 years and $40 \%$ were women. In the propensity-weighted cohort, the primary outcome occurred in $6.5 \%$ in the ACEl group and $5.7 \%$ in the ARB group at 1 year (HR comparing ACEl with ARB 1.14, 95\% $\mathrm{Cl} 1.05$ to $1.23, \mathrm{p}<0.001)$. At 3 years, the primary outcome occurring in $16.0 \%$ with ACEls and $15.1 \%$ with ARBs (HR 1.07; $95 \% \mathrm{Cl} 1.02$ to 1.12; $\mathrm{p}<0.001$ ). A significant interaction with sex was observed, with women prescribed ACEls having a higher hazards (HR 1.17; $95 \% \mathrm{Cl} 1.10$ to 1.26) compared with ARBs, while no significant difference was seen among men (HR 1.00; $95 \% \mathrm{Cl} 0.93$ to 1.06 , interaction $\mathrm{p}<0.001$ ).

Conclusions Despite previous concerns regarding ARBs, we found that they had slightly lower rates of adverse clinical cardiovascular outcomes among older patients with MI compared with ACEls. The observed difference in clinical outcomes may be related to a sex difference in effectiveness.

\section{INTRODUCTION}

Medications that inhibit the renal angiotensin aldosterone system such as ACE inhibitors (ACEIs) and angiotensin receptor blockers (ARBs) are commonly recommended to treat patients with myocardial infarction (MI). ${ }^{12}$ Although more than 100 randomised trials have enrolled more than 250000 patients without heart failure to study ACEIs and ARBs, ${ }^{3}$ whether these medications are

\section{Key questions}

What is already known about this subject?

- Practice guidelines recommend ACE inhibitors (ACEls) and angiotensin receptor blockers (ARBs) for patients with coronary artery disease. However whether these medications are similarly effective is still uncertain.

What does this study add?

- We conducted a population-based study by including close to 60000 older patients with myocardial infarction.

- We found that ARBs actually had had slightly lower rates of adverse clinical cardiovascular outcomes compared with ACEls. In addition, we observed a sex difference that women appeared to have lower risk when prescribed ARBs.

How might this impact on clinical practice?

- Despite controversies about whether ARBs are effective in myocardial infarction, our study demonstrated that they were not substantially different from ACEls. Further study should evaluate the potential sex difference between these drugs.

similarly effective in a broad range of patients with cardiovascular conditions continues to be a subject of intense debate. ${ }^{45}$ The term 'ARB-MI paradox' was coined after the Valsartan Antihypertensive Long-Term Use Evaluation trial demonstrated a $19 \%$ significantly increased risk of MI in the valsartan group as compared with amlodipine among patients with hypertension at high cardiovascular risk. ${ }^{6}$ This controversy sparked the efforts of numerous investigators to combine all available data to understand the safety and effectiveness of ACEIs relative to that of ARBs. Findings have diverged substantially, with some data showing ACEIs are associated with improved outcomes compared with ARBs ${ }^{8-10}$ while other data show ACEIs are not significantly different from ARBs. ${ }^{3}$ Some 
studies have even concluded that ARBs are not significantly different compared with placebo. ${ }^{8911}$

One of the difficulties in comparing the safety and effectiveness of ACEIs relative to ARBs is the paucity of head-to-head clinical trials. In fact, only three large trials have directly compared ACEIs and ARBs in patients with coronary artery disease. ${ }^{12-14}$ Of these trials, two enrolled patients had acute MI complicated with heart failure, ${ }^{12}{ }^{13}$ and the other enrolled patients were at high risk of vascular events. ${ }^{14}$ Moreover, two of these trials were conducted close to two decades ago. ${ }^{12}{ }^{13}$ It is difficult to know whether the results of these older trials are still applicable in contemporary clinical practice. Given that ACEIs and ARBs are commonly prescribed in the treatment of patients with cardiovascular disease, we sought to address this gap in knowledge by comparing the realworld effectiveness of ACEIs and ARBs in a large population-based cohort with prior MI using longitudinal linked databases in Ontario, Canada.

\section{METHODS}

\section{Design and data sources}

We conducted a retrospective cohort study using population-based databases in Ontario, Canada. The Cardiovascular Health in Ambulatory Care Research Team (CANHEART) cohort was created by merging 17 different longitudinal individual-level data sources. ${ }^{15}$ The data sources used for this study have been described previously with additional information on our study website (www. canheart.ca). ${ }^{15-19}$ Primary databases that were used for this study include (1) Ontario Health Insurance Plan, a registry of all physician billings in Ontario; (2) Ontario Drug Benefit, a registry of outpatient prescriptions; (3) Registered Persons Database of Ontario, a registry of the demographics of Ontario residents; (4) Canadian Institute for Health Information (CIHI) Discharge Abstract Database, a database used to identify prior cardiac risk factors, comorbidities and hospitalisations; (5) Statistics Canada census data were used for neighbourhood income data; and (6) Office of the Registrar General Deaths database was used to ascertain cause of death. These datasets were linked using unique encoded identifiers and analysed at the Institute for Clinical Evaluative Sciences.

\section{Study sample}

Ontario residents who were alive on 1 April 2012 (index date), older than 65 years and had a valid health insurance number were eligible for inclusion in the study cohort. Patients who were prescribed an ACEI or an ARB in the 100 days before 1 April 2012 were considered for inclusion. An age limit was used in our study because the Ontario Drug Benefit database includes only prescription drug information for those aged 65 years and above. The cohort was defined as those who had a hospitalisation for MI in the 10 years prior to the index date using International Classification of Disease 10th version codes I21 and I22.

\section{ACEls and ARBs}

ACEIs and ARBs that were available on the Ontario drug formulary within 100 days of the index date were included in the study. ACEIs included were benazepril, captopril, cilazapril, enalapril, fosinopril, lisinopril, perindopril, quinapril, ramipril and trandolapril. The ARB group included candesartan, eprosartan, irbesartan, losartan, olmesartan, telmisartan and valsartan. Different formulations (eg, enalapril maleate and enalapril sodium) and manufacturers (ie, brand and generic) were grouped together, while intravenous drugs were excluded. Combination drugs were treated as ACEIs or ARBs, depending on the respective formulation.

\section{Outcomes}

The primary outcome of this study was a composite of cardiovascular mortality, hospitalisation for MI and unstable angina at 3 years. We also examined this composite outcome at 1 year. Secondary outcomes included hospitalisation for MI or angina, and hospitalisation for heart failure at 1 and 3 years. Cardiovascular mortality was ascertained by the Office of the Registrar General Deaths database. Hospitalisation for cardiac conditions was ascertained by CIHI discharge abstract database.

\section{Statistical analysis}

Demographic and clinical characteristics of patients prescribed ACEIs and ARBs were compared using $\chi^{2}$ tests for categorical variables and the Wilcoxon rank-sum test for continuous variables. To adjust for potential confounding between the treatment groups, we used the inverse probability of treatment weighting using the propensity score to account for observed systematic differences in baseline covariates between treatment groups. ${ }^{20}{ }^{21}$ The propensity score, which was defined as the probability of receiving ACEIs, was estimated using a logistic regression model in which treatment group (ACEI vs ARB) was regressed on the following characteristics related to the likelihood of being prescribed one of the drugs: demographics (age, sex, income, rural residency), timing of MI from index data, cardiac risk factors (hypertension, diabetes, hyperlipidemia), cardiovascular conditions (atrial arrhythmia, cerebrovascular disease, heart failure, peripheral vascular disease, shock) and medical comorbidities (anaemia, cancer, chronic obstructive pulmonary disease, liver disease, peptic ulcer disease, renal disease), cardiac procedures (cardiac catheterisation, percutaneous coronary intervention, coronary arterial bypass grafting) and prior medication (statins, beta blockers, diuretics, clopidogrel, calcium channel blockers, long-acting nitrates, warfarin).

Patients were then weighted by the inverse of the probability of receiving the treatment that they received. ${ }^{20}$ Balance of baseline covariates between the treatment groups in the weighted cohort was assessed by computing weighted standardised differences, with differences of less than 0.1 indicating good balance. ${ }^{22}$ The effect of ACEIs 


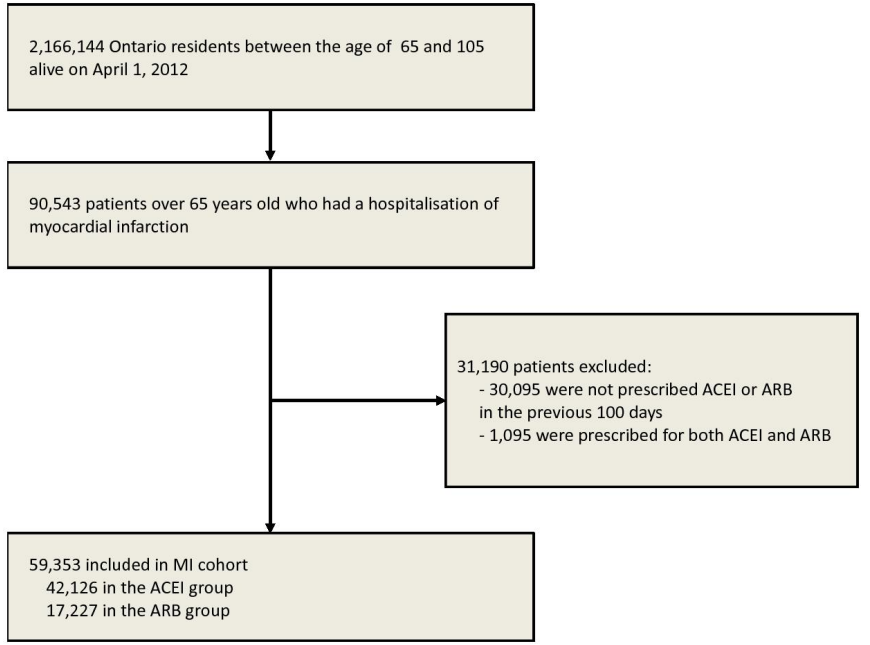

Figure 1 Creation of the study cohort using the entire Ontario population aged 65 to 105 years who were alive on 1 April 2012. A total of 59353 patients were included in our study cohort after inclusion and exclusion criteria were applied. ACEI, ACE inhibitor; ARB, angiotensin receptor blocker

on the hazard of clinical outcomes was estimated using a cause-specific proportional hazards model in which the hazard of the outcome was regressed on the receipt of ARBs as the reference. These models accounted for the competing risk of non-cardiovascular death. The inverse probability treatment weights were incorporated and a robust variance estimator was used. ${ }^{23}$ We also compared ACEIs and ARBs in the following predefined subgroups: age ( $<75, \geq 75$ years), sex (male, female), prior diabetes, and prior heart failure for the composite outcome of cardiovascular mortality, MI or unstable angina at 3 years. This was achieved by examining the interaction between treatment status and the subgroup variables of interest within the propensity-weighted cohort.

Statistical analyses were conducted using SAS V.9.3 (SAS Institute, Cary, North Carolina, USA). A two-sided $p$ value of $<0.05$ was considered statistically significant. The use of data in this project was authorised under section 45 of Ontario's Personal Health Information Protection Act, which does not require review by a Research Ethics Board.

\section{RESULTS}

\section{Creation of the study cohort}

Among the 2166144 individuals who were between the ages of 65 and 105 years on 1 April 2012, 90543 patients had been hospitalised with an MI in the past 10 years (figure 1). After excluding 30095 patients who were not prescribed an ACEI or an ARB, and 1095 patients who were prescribed both concurrently, our final cohort included 59353 patients; $42126(71.0 \%)$ were prescribed an ACEI and 17227 (29.0\%) were prescribed an ARB.

The most commonly prescribed ACEI in our cohort in descending order was ramipril $(67.2 \%)$, perindopril $(21.8 \%)$, lisinopril $(3.1 \%)$, enalapril $(2.9 \%)$ and quinapril $(1.9 \%)$, while the most commonly prescribed ARBs were candesartan (25.6\%), valsartan (23.2\%), irbesartan (18.9\%), telmisartan (17.3\%) and losartan $(12.4 \%)$ (online supplementary table 1 ).

\section{Characteristics before and after propensity weighting}

Prior to propensity score weighting, patients prescribed ARBs were slightly older (77.4 years vs 76.9 years), had higher rates of cardiac risk factors, including diabetes (49.2\% vs $43.9 \%)$, hypertension $(94.7 \%$ vs $88.6 \%)$, dyslipidemia (58.6\% vs $55.3 \%$ ) and renal disease $(11.3 \%$ vs $8.3 \%$ ), and higher Charlson score compared with those prescribed ACEIs (online supplementary table 2).

After propensity score weighting, the ACEI and the ARB group were well balanced, with the standardised differences being less than 0.1 for all characteristics (table 1). In the weighted sample, the mean age was $77,59.5 \%$ of patients were men, $45.6 \%$ had diabetes, $90.4 \%$ had hypertension, $56.3 \%$ had dyslipidemia, $9.3 \%$ had renal disease and $26.2 \%$ had a history of heart failure. The majority of patients with MI patients were also prescribed statins $(84.1 \%)$ and beta blockers $(70.3 \%)$.

\section{Clinical outcomes of ACEls versus ARBs}

At 1 year, the primary outcome of cardiovascular death or hospitalisation for MI or unstable angina occurred in $6.5 \%$ of patients in those taking ACEI and $5.7 \%$ in those taking ARB (HR 1.14; 95\% CI 1.05 to 1.23 ; $\mathrm{p}=<0.001$ ) (table 2). This trend persisted at 3 years, with the primary outcome occurring in $16.0 \%$ of those taking ACEI and $15.1 \%$ of those taking ARB (HR 1.07; 95\% CI 1.02 to 1.12; $\mathrm{p}=0.008$ ). The corresponding Kaplan-Meier curve is shown in figure 2 . The rate of cardiovascular death was significant higher in the ACEI group compared with the ARB group (table 2). At 1 year, cardiovascular death was $3.7 \%$ in the ACEI group and $2.8 \%$ in the ARB group (HR $1.31 ; 95 \%$ CI 1.18 to $1.45 ; \mathrm{p}<0.001)$. At 3 years, cardiovascular death occurred in $9.9 \%$ of the ACEI group and in $8.6 \%$ of the ARB group (HR 1.16; 95\% CI 1.09 to 1.23; $\mathrm{p}<0.001)$. We also observed lower all-cause mortality in the ARB group at $6.6 \%$ at 1 year (vs $8.2 \%$ in the ACEI group) and at 3 years (20.0\% in the ARB group vs $22.4 \%$ in the ACEI group). There was no significant difference observed in hospitalisation for MI or angina, or heart failure at 1 or 3 years.

\section{Subgroup analyses}

We performed subgroup analyses to investigate the potential difference in clinical outcomes between ACEIs and ARBs among predefined subgroups (table 3). Subgroup analyses based on age, diabetes status and prior heart failure did not show any significant interaction. In contrast, a significant sex difference was observed in which women had a higher HR associated with ACEIs $(1.17 ; 95 \%$ CI 1.10 to 1.26$)$, while there was no significant difference between the treatment groups among men (HR 1.00; 95\% CI 0.93 to $1.06, \mathrm{p}<0.001$ for interaction). To explore this potential discrepancy, we further explored 
Table 1 Baseline characteristics after propensity score weighting

\begin{tabular}{llll}
\hline Characteristics & $\begin{array}{l}\text { ACEls } \\
(\%)\end{array}$ & $\begin{array}{l}\text { ARBs } \\
(\%)\end{array}$ & $\begin{array}{l}\text { Standardised } \\
\text { difference }\end{array}$ \\
\hline Age (years), mean \pm SD & $77.0 \pm 9.5$ & $77.1 \pm 14.3$ & 0.008 \\
\hline Men & 59.6 & 59.5 & 0.002 \\
Rural resident & 15.7 & 15.7 & 0.001 \\
\hline $\begin{array}{l}\text { Timing of Ml in months, } \\
\text { mean } \pm \text { SD }\end{array}$ & $53.7 \pm 42.5$ & $54.0 \pm 65.0$ & 0.008
\end{tabular}

\begin{tabular}{|c|c|c|c|}
\hline \multicolumn{4}{|l|}{$\begin{array}{l}\text { Cardiovascular } \\
\text { comorbidities }\end{array}$} \\
\hline $\begin{array}{l}\text { Chronic ischaemic } \\
\text { heart disease }\end{array}$ & 82.5 & 82.1 & 0.011 \\
\hline Angina & 24.6 & 26.2 & 0.037 \\
\hline Atrial fibrillation/flutter & 22.2 & 22.4 & 0.005 \\
\hline Diabetes & 45.5 & 45.6 & 0.003 \\
\hline Heart failure & 26.1 & 26.5 & 0.008 \\
\hline Hypertension & 90.4 & 90.4 & 0.001 \\
\hline Dyslipidemia & 56.3 & 56.2 & 0.001 \\
\hline $\begin{array}{l}\text { Peripheral vascular } \\
\text { disease }\end{array}$ & 7.1 & 7.2 & 0.002 \\
\hline $\begin{array}{l}\text { Cerebrovascular } \\
\text { disease }\end{array}$ & 9.4 & 9.4 & $<0.001$ \\
\hline $\begin{array}{l}\text { Stroke/transient } \\
\text { ischaemic attack }\end{array}$ & 7.7 & 7.7 & $<0.001$ \\
\hline Shock & 5.0 & 4.9 & 0.002 \\
\hline \multicolumn{4}{|l|}{ Medical comorbidities } \\
\hline Renal disease & 9.2 & 9.3 & 0.004 \\
\hline Cancer & 11.1 & 11.1 & 0.001 \\
\hline $\begin{array}{l}\text { Chronic obstructive } \\
\text { pulmonary disease }\end{array}$ & 13.3 & 13.3 & $<0.001$ \\
\hline Liver disease & 1.0 & 1.0 & $<0.001$ \\
\hline Peptic ulcer disease & 4.0 & 4.0 & 0.001 \\
\hline Anaemia/blood disease & 22.1 & 22.4 & 0.006 \\
\hline Charlson score, mean $\pm S D$ & $2.9 \pm 2.4$ & $2.9 \pm 3.6$ & 0.006 \\
\hline \multicolumn{4}{|l|}{$\begin{array}{l}\text { Prior cardiac invasive } \\
\text { procedures }\end{array}$} \\
\hline $\begin{array}{l}\text { Percutaneous coronary } \\
\text { intervention }\end{array}$ & 46.8 & 46.5 & 0.006 \\
\hline $\begin{array}{l}\text { Coronary artery bypass } \\
\text { grafting }\end{array}$ & 20.4 & 20.5 & 0.002 \\
\hline $\begin{array}{l}\text { Coronary } \\
\text { catheterisation }\end{array}$ & 80.7 & 80.4 & 0.005 \\
\hline \multicolumn{4}{|l|}{ Medication use } \\
\hline Statins & 84.0 & 84.1 & 0.001 \\
\hline Beta blocker & 70.3 & 70.3 & 0.001 \\
\hline Diuretics & 43.8 & 43.8 & $<0.001$ \\
\hline Clopidogrel & 31.4 & 31.1 & 0.006 \\
\hline $\begin{array}{l}\text { Calcium channel } \\
\text { blockers }\end{array}$ & 30.5 & 30.5 & $<0.001$ \\
\hline
\end{tabular}

Continued

\begin{tabular}{|lllc|}
\hline Table 1 Continued & & & \\
Characteristics & $\begin{array}{l}\text { ACEls } \\
(\%)\end{array}$ & $\begin{array}{l}\text { ARBs } \\
\text { (\%) }\end{array}$ & $\begin{array}{l}\text { Standardised } \\
\text { difference }\end{array}$ \\
\hline Nitrates & 19.2 & 19.4 & 0.005 \\
Warfarin & 12.3 & 12.4 & 0.003 \\
Spiroloactone & 5.2 & 4.5 & 0.030 \\
\hline
\end{tabular}

ACEI, ACE inhibitor; ARB, angiotensin receptor blocker; MI, myocardial infarction.

potential difference in dosages and medication adherence by sex. The median dosage of ramipril in women was $5 \mathrm{mg}$, while the median dosage was $7.5 \mathrm{mg}$ in men. In contrast, median dose of ARBs was identical between men and women. Women appeared to have higher adherence for ARBs than ACEIs. The proportional days covered for ACEI was $74.9 \%$ in women and $77.4 \%$ in men, and $76.8 \%$ for ARB in women and $75.9 \%$ in men.

\section{DISCUSSION}

Using a population-based level big data cohort in Ontario, Canada, we performed a comprehensive evaluation comparing the clinical outcomes of ACEIs versus ARBs in patients with prior MI. Despite the concern of an ARB-MI paradox and that it may not be effective in coronary artery disease, we found that ARBs were actually associated with slightly lower rates of cardiovascular death as compared with patients treated with ACEI. Heterogeneity in the treatment effects was seen in that women had a significantly lower risk of events when prescribed ARBs compared with ACEIs, while there was no difference in the primary outcome between ACEI and ARB groups for men. Our findings should help alleviate concerns regarding the potential harmful effects associated with ARBs.

It has been widely believed that ACEIs are more effective than ARBs in a broad range of patients with cardiovascular diseases. ${ }^{58}$ Practice guidelines have consistently recommended using ARBs only when patients are not able to tolerate the side effects associated with ACEIs. ${ }^{12}$ Recently, Messerli and colleagues has challenged this conventional wisdom. ${ }^{4}$ They pointed out that the relatively efficacy of ACEIs and ARBs was mainly derived from comparisons of trials that compared ACEIs versus placebo, and ARBs versus placebo. ${ }^{4}$ Given the fact that trials of ACEIs were conducted almost a decade before ARBs, the enrolled patients were rarely treated with statin therapy or other optimal medical therapy, and had almost twice the event rates of patients enrolled in trials of ARBs. As a result, it is very plausible that the temporal discrepancy in ACEI and ARB trials may explain why ACEIs have previously been shown to have larger benefits as compared with ARBs. ${ }^{34}$

\section{Prior studies of ACEl versus ARBs in MI}

Indeed, the three landmark trials that performed head-tohead comparisons between ACEIs and ARBs-Valsartan in Acute Myocardial Infarction (VALIANT), Optimal 
Table 2 Outcomes in the ACEI and ARB group

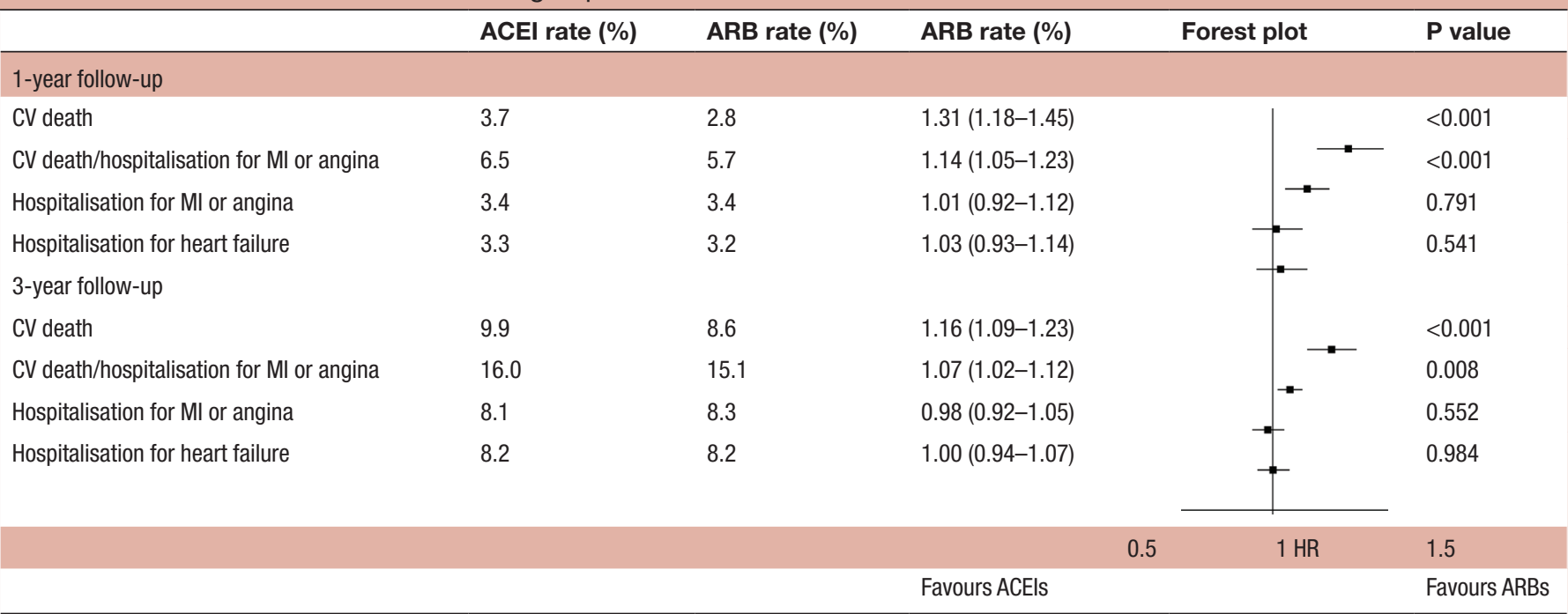

Higher HR indicates better outcomes associated with ARBs.

ACEI, ACE inhibitor; ARB, angiotensin receptor blocker; CV, cardiovascular; MI, myocardial infarction.

Trial in Myocardial Infarction with the Angiotensin II Antagonist Losartan (OPTIMAAL), and ongoing Telmisartan Alone and in Combination with Ramipril Global Endpoint Trial (ONTARGET) —all showed no significant outcome difference between patients prescribed ACEIs and ARBs. ${ }^{12-14}$ While findings from our study may appear be at odds with these trials, patients included in our study differed substantially from prior trials. First, the mean age of our cohort was more than 10 years older than these clinical trials and we had significantly higher proportion of women at $40 \%$ as compared with these three trials that ranged from $27 \%$ to $32 \%$. Second, we included patients who had prior MI in the past 10 years while VALIANT and OPTIMAAL were trials of acute MI with heart failure. Finally, the use of statins has substantially increased where

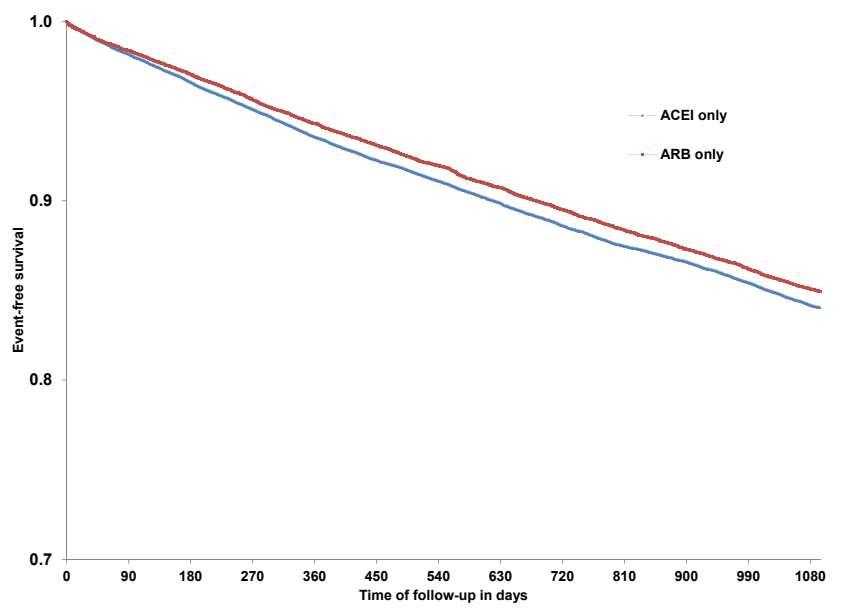

Figure 2 Kaplan-Meier curve of the primary outcome in patients prescribed ACE inhibitor (ACEI) and angiotensin receptor blocker (ARB). Y-axis shows event rate rates and $\mathrm{X}$-axis shows time in days after assembling the study cohort. Blue line depicts event rates for ACEI and red line depicts event rates for ARBs. we observed $84 \%$ prescription in our cohort; the OPTIMAAL trial reported only about $30 \%$ were prescribed statins. $^{12}$

An emerging number of observational studies have suggested that outcomes of patients treated with ARBs may have better outcomes compared with ACEIs. ${ }^{24-26}$ Using the Reduction of atherothrombosis for Continued Health registry, Potier and colleagues performed an analysis including 40625 patients who were at high cardiovascular risk and found a $10 \%$ reduction in the risk of a composite of cardiovascular mortality, MI, stroke or hospitalisation with ARB compared with ACEI at 4 years. ${ }^{26}$ Similarly, Padwal et al evaluated 87772 diabetic patients without prior MI using a large US claims database and found that ARBs were associated with a $10 \%$ reduction in all-cause mortality and all-cause hospitalisation. ${ }^{25} \mathrm{~A}$ smaller study from Korea also demonstrated that ARBs may be associated with improved clinical outcomes in patients with MI without heart failure or ventricular dysfunction. ${ }^{24}$ By focusing on patients with prior MI, our study adds to the contemporary literature to suggest potential benefits associated with ARBs as compared with ACEIs.

\section{Sex difference of ACEl and ARB}

We are unaware of any studies that have evaluated the potential sex difference between ACEIs and ARBs among patients with coronary artery disease. An observational study that evaluated sex difference between ACEIs and ARBs in patients with heart failure also found that women had significant survival improvement with ARBs, but not in men. ${ }^{27}$ In our study, we found that women were prescribed lower dose of ramipril relative to men. Second, we also found that women have greater adherence to ARBs as compared with ACEs. Others have postulated that women have greater response in blood pressure reduction in ARBs as a potential mechanism 


\begin{tabular}{|c|c|c|c|c|}
\hline & ACEI rate $\%(95 \% \mathrm{Cl})$ & ARB rate $\%(95 \% \mathrm{Cl})$ & HR $(95 \% \mathrm{Cl}) \dagger$ & Interaction $p$ value \\
\hline \multicolumn{5}{|l|}{ Age (years) } \\
\hline$<75$ & 10.3 (9.8 to 10.7$)$ & 10.1 (9.4 to 10.8$)$ & 1.02 (0.93 to 1.12) & \multirow[t]{2}{*}{0.155} \\
\hline$\geq 75$ & 20.4 (19.9 to 20.9) & 18.8 (18.0 to 19.6) & $1.10(1.04$ to 1.17$)$ & \\
\hline \multicolumn{5}{|l|}{ Sex } \\
\hline Female & 18.0 (17.4 to 18.6$)$ & 15.6 (14.7 to 16.5$)$ & $1.17(1.10$ to 1.26$)$ & \multirow[t]{2}{*}{$<0.001$} \\
\hline Male & 14.6 (14.1 to 15.0$)$ & $14.7(14.0$ to 15.4$)$ & $1.00(0.93$ to 1.06$)$ & \\
\hline \multicolumn{5}{|c|}{ Prior diabetes } \\
\hline Yes & 18.9 (18.4 to 19.5$)$ & $18.1(17.2$ to 19.0$)$ & 1.05 (0.99 to 1.12$)$ & \multirow[t]{2}{*}{0.576} \\
\hline No & 13.5 (13.0 to 14.0$)$ & 12.6 (11.9 to 13.3$)$ & $1.08(1.01$ to 1.17$)$ & \\
\hline \multicolumn{5}{|c|}{ Prior heart failure } \\
\hline Yes & 28.7 (27.8 to 29.6) & 26.4 (25.1 to 27.8$)$ & $1.12(1.04$ to 1.20$)$ & \multirow[t]{2}{*}{0.209} \\
\hline No & 11.7 (11.4 to 12.1$)$ & $11.2(10.7$ to 11.8$)$ & 1.05 (0.98 to 1.12) & \\
\hline
\end{tabular}

*Primary outcome defined as cardiovascular death, rehospitalisation for myocardial infarction and unstable angina.

†ARB inhibitor was the reference group.

ACEI, ACE inhibitor; ARB, angiotensin receptor blocker.

of sex difference, and there is a diminishing effect of ACEI in women over time. ${ }^{28}$ However, since this was an incidental finding, we are cautious with respect to its interpretation and suggest future study for additional investigations.

\section{Study limitations}

Several potential limitations of our study merit consideration. First, despite the availability of a large amount of clinical detail and using sophisticated propensity weighting, it is still possible that the difference we observed between the treatment groups was a result of selection bias. However, the influence of selection bias is likely to be greater in studies comparing an active intervention with no treatment than in studies like ours that compared two active interventions with similar indications. Furthermore, in our study, patients prescribed ARBs were sicker prior to propensity weighting, as they were older and had more comorbidity, indicating that ARBs were not selectively prescribed to lower-risk patients with MI. Second, we did not have information regarding whether patients were prescribed ARBs because of side effects associated with ACEIs and whether they were prescribed as firstline therapy. Therefore, our study should not be interpreted as advocating ARBs should be a first-line therapy in patients with MI. Third, due to the number of formulations of ACEIs and ARBs on the market, we combined medications into two groups so that we can perform our analyses. Our finding may not be applicable to all jurisdictions if the composition of these medications is vastly different. Finally, our study only included patients over 65 years of age because of the unavailability of prescription information on younger patients. Further studies are needed to examine whether similar results are seen among younger patients.

\section{CONCLUSIONS}

Although many are still concerned with an ARB-MI paradox, our study of close to 60000 patients with MI should serve as reassurance that ARBs are not associated with adverse outcomes compared with ACEIs. Potential benefits of ARBs as compared with ACEIs in older women with MI should be further evaluated.

Acknowledgements This study was supported by the ICES, which is funded by an annual grant from the Ontario Ministry of Health and Long-Term Care (MOHLTC).

Contributors All authors contributed substantially to the manuscript, drafted the article or revised it critically for important intellectual content and gave final approval for the submission.

Funding This study was funded by a grant (G-14-0005977) from the Heart and Stroke Foundation (HSF) of Canada and a Foundation grant (FDN-154333) from the Canadian Institutes of Health Research.

Disclaimer The opinions, results and conclusions reported in this article are those of the authors and are independent from the funding sources. No endorsement by ICES or the MOHLTC is intended or should be inferred. Parts of this material are based on data and information compiled and provided by $\mathrm{CIHI}$. The analyses, conclusions, opinions and statements expressed herein are those of the authors and not necessarily those of $\mathrm{ClHI}$.

Competing interests None declared.

Patient consent for publication Not required.

Provenance and peer review Not commissioned; externally peer reviewed.

Data sharing statement Data may be obtained from a third party and are not publicly available.

Open access This is an open access article distributed in accordance with the Creative Commons Attribution Non Commercial (CC BY-NC 4.0) license, which permits others to distribute, remix, adapt, build upon this work non-commercially, and license their derivative works on different terms, provided the original work is properly cited, appropriate credit is given, any changes made indicated, and the use is non-commercial. See: http://creativecommons.org/licenses/by-nc/4.0/.

\section{REFERENCES}

1. O'Gara PT, Kushner FG, Ascheim DD, et al. 2013 ACCF/AHA guideline for the management of ST-elevation myocardial infarction: a report of the American College of Cardiology Foundation/American 
Heart Association Task Force on Practice Guidelines. Circulation 2013;127:e362-425.

2. Amsterdam EA, Wenger NK, Brindis RG, et al. 2014 AHA/ACC guideline for the management of patients with non-ST-elevation acute coronary syndromes: a report of the American College of Cardiology/American Heart Association Task Force on Practice Guidelines. Circulation 2014;130:e344-426.

3. Bangalore S, Fakheri R, Toklu B, et al. Angiotensin-converting enzyme inhibitors or angiotensin receptor blockers in patients without heart failure? Insights from 254,301 patients from randomized trials. Mayo Clin Proc 2016;91:51-60.

4. Messerli FH, Bangalore S. Angiotensin receptor blockers reduce cardiovascular events, including the risk of myocardial infarction. Circulation 2017;135:2085-7.

5. Strauss MH, Hall AS. Angiotensin receptor blockers do not reduce risk of myocardial infarction, cardiovascular death, or total mortality: further evidence for the ARB-MI paradox. Circulation 2017;135:2088-90.

6. Verma S, Strauss M. Angiotensin receptor blockers and myocardial infarction. BMJ 2004;329:1248-9.

7. Julius S, Kjeldsen SE, Weber M, et al. Outcomes in hypertensive patients at high cardiovascular risk treated with regimens based on valsartan or amlodipine: the VALUE randomised trial. Lancet 2004;363:2022-31.

8. Epstein BJ, Gums JG. Angiotensin receptor blockers versus ACE inhibitors: prevention of death and myocardial infarction in high-risk populations. Ann Pharmacother 2005;39:470-80.

9. Hoang V, Alam M, Addison D, et al. Efficacy of angiotensinconverting enzyme inhibitors and angiotensin-receptor blockers in coronary artery disease without heart failure in the modern statin era: a meta-analysis of randomized-controlled trials. Cardiovasc Drugs Ther 2016;30:189-98.

10. Strauss MH, Hall AS. Angiotensin receptor blockers may increase risk of myocardial infarction: unraveling the ARB-MI paradox. Circulation 2006;114:838-54.

11. Cheng J, Zhang W, Zhang X, et al. Effect of angiotensin-converting enzyme inhibitors and angiotensin II receptor blockers on all-cause mortality, cardiovascular deaths, and cardiovascular events in patients with diabetes mellitus. JAMA Intern Med 2014:174:773-85.

12. Dickstein K, Kjekshus J. Effects of losartan and captopril on mortality and morbidity in high-risk patients after acute myocardial infarction: the OPTIMAAL randomised trial. The Lancet 2002;360:752-60.

13. Pfeffer MA, McMurray JJV, Velazquez EJ, et al. Valsartan, captopril, or both in myocardial infarction complicated by heart failure, left ventricular dysfunction, or both. N Engl J Med 2003;349:1893-906.

14. Investigators $\mathrm{O}$, Yusuf $\mathrm{S}$, Teo KK, et al. Telmisartan, ramipril, or both in patients at high risk for vascular events. N Engl $\mathrm{J}$ Med 2008;358:1547-59.
15. JV T, Chu A, Donovan LR, et al. The Cardiovascular Health in Ambulatory Care Research Team (CANHEART): using big data to measure and improve cardiovascular health and healthcare services. Circ Cardiovasc Qual Outcomes 2015;8:204-12.

16. DT K, Alter DA, Guo H, et al. High-density lipoprotein cholesterol and cause-specific mortality in individuals without previous cardiovascular conditions: the CANHEART study. J Am Coll Cardiol 2016;68:2073-83.

17. Yan AT, Koh M, Chan KK, et al. Association between cardiovascular risk factors and aortic stenosis: the CANHEART Aortic Stenosis Study. J Am Coll Cardiol 2017;69:1523-32.

18. DT K, Krumholz HM, JV T, et al. Clinical outcomes of Plavix and generic clopidogrel for patients hospitalized with an acute coronary syndrome. Circ Cardiovasc Qual Outcomes 2018;11:e004194.

19. Azizi P, Jackevicius $C$, Chong A, et al. Sex-differences in efficacy of angiotensin converting enzyme inhibitors and angiotensin receptor blockers in patients with prior myocardial infarction. Can J Cardiol 2018;34.

20. Austin PC. A tutorial and case study in propensity score analysis: an application to estimating the effect of in-hospital smoking cessation counseling on mortality. Multivariate Behav Res 2011;46:119-51.

21. Cole SR, Hernán MA. Adjusted survival curves with inverse probability weights. Comput Methods Programs Biomed 2004;75:45-9.

22. Austin PC, Stuart EA. Moving towards best practice when using inverse probability of treatment weighting (IPTW) using the propensity score to estimate causal treatment effects in observational studies. Stat Med 2015;34:3661-79.

23. Austin PC. The performance of different propensity score methods for estimating marginal hazard ratios. Stat Med 2013;32:2837-49.

24. Lee $\mathrm{JH}, \mathrm{Bae} \mathrm{MH}$, Yang $\mathrm{DH}$, et al. Angiotensin II type 1 receptor blockers as a first choice in patients with acute myocardial infarction. Korean J Intern Med 2016;31:267-76.

25. Padwal R, Lin M, Eurich DT. The comparative effectiveness of angiotensin-converting enzyme inhibitors and angiotensin II receptor blockers in patients with diabetes. $J$ Clin Hypertens 2016;18:200-6.

26. Potier L, Roussel R, Elbez Y, et al. Angiotensin-converting enzyme inhibitors and angiotensin receptor blockers in high vascular risk. Heart 2017;103:1339-46.

27. Hudson M, Rahme E, Behlouli $\mathrm{H}$, et al. Sex differences in the effectiveness of angiotensin receptor blockers and angiotensin converting enzyme inhibitors in patients with congestive heart failure - a population study. Eur J Heart Fail 2007;9:602-9.

28. Matsui K, Kim-Mitsuyama S, Ogawa H, et al. Sex differences in response to angiotensin II receptor blocker-based therapy in elderly, high-risk, hypertensive Japanese patients: a subanalysis of the OSCAR study. Hypertens Res 2014;37:526-32. 